\title{
Magnetic Performance of New Fermilab High Gradient Quadrupoles
}

\author{
R. Hanft, B. C. Brown, J. A. Carson, S. A. Gourlay, M. J. Lamm, \\ A. D. McInturff, A. Mokhtarani, A. Riddiford \\ Fermi National Accelerator Laboratory \\ P.O. Box 500 \\ Batavia, Illinois 60510
}

May 1991

* Presented at the IEEE Particle Accelerator Conference, May 6 -9, 1991, San Francisco, CA. 


\title{
Magnetic Performance Of New Fermilab High Gradient Quadrupoles
}

\author{
R. Hanft, B. C. Brown, J. A. Carson, S. A. Gourlay, M. J. Lamm \\ A. D. McInturf, A. Mokhtarani, A. Riddiford \\ Fermi National Accelerator Laboratory* \\ P.O. Box 500 \\ Batavia, Illinois 60510
}

\begin{abstract}
Abstraet
For the Fermilab Tevatron low beta insertions installed in 1990-1991 as part of a luminosity upgrade there were built approximately 35 superconducting cold iron quadrupoles utilising a two layer $\cos 2 \theta$ coil geometry with $76 \mathrm{~mm}$ diameter aperature. The field harmonics and strengths of these magnets obtained by measurement at cryogenic conditions are presented. Evidence for a longitudinal periodic structure in the remnant field is shown.
\end{abstract}

\section{INTRODUCTION}

The low-beta insertions installed in the Fermilab Tevatron in 1990-1991 at the Bo (CDF) and $\mathrm{DO}$ interaction regions include several devices containing new high gradient quadrupoles of the socalled " 717 " design cross section [1]. Table 1 enumerates the devices containing " 717 " quadrupoles; it can be seen that only four different magnetic lengths are involved. The Q1 and Q5 magnets were made so to be interchangeable in the accelerator. The TSK and TSJ devices are spool pieces similar to the conventional Tevatron spools, but one nested weak corrector package is replaced with a strong " 717 " trim quadrupole.

\section{Table 1}

Low Beta Insertion Components Containing "717" Cross Section Design Quadrupoles

\begin{tabular}{|c|c|c|c|c|}
\hline $\begin{array}{l}\text { Lattice } \\
\text { Designation }\end{array}$ & $\begin{array}{l}\text { Nominal } \\
\text { Magnetic } \\
\text { Length } \\
\text { (m) }\end{array}$ & $\begin{array}{r}\mathrm{Na} \\
\mathbf{M} \\
\text { Built }\end{array}$ & $\begin{array}{l}\text { ber of } \\
\text { znets } \\
\text { Tested }\end{array}$ & $\begin{array}{c}\text { Excitation } \\
\text { Current at } \\
1 \mathrm{TeV} \\
\text { (A) }\end{array}$ \\
\hline $\begin{array}{l}\text { TSJ } \\
\text { TSK } \\
\text { Q1/Q5 } \\
\text { Q2 } \\
\text { Q4 } \\
\text { Q3 }\end{array}$ & $\begin{array}{l}0.61 \\
0.61 \\
1.40 \\
3.35 \\
3.35 \\
5.89\end{array}$ & $\begin{array}{r}3 \\
4 \\
12 \\
5 \\
5 \\
5\end{array}$ & $\begin{array}{r}3 \\
5 \\
11 \\
4 \\
5 \\
5\end{array}$ & $\begin{array}{c}4832 \\
4832 \\
2011 / 2821 \\
4811 \\
4811 \\
4746\end{array}$ \\
\hline
\end{tabular}

This quadrupole is a cold iron two shell magnet in an SSC dipole-like cryostat. Each pole has 19 inner and 28 outer layer turns of 36 strand Rutherford

\footnotetext{
Operated by Univeraitice Reacarch Aasociation, Inc., under contract with U.S Department of Energy.
}

atyle superconducting NbTi cable. The nominal copper to superconductor ratio is 1.5:1. The strand insulation is copper oxide. The cable twist pitch is $72 \mathrm{~mm}$ (except for $81 \mathrm{~mm}$ in a few reels at the end of the cabling run). The nominal gradient is $29.1 \mathrm{~T} / \mathrm{m} / \mathrm{kA}$. At $4.6 \mathrm{~K}$ operating temperature these quadrupoles quench around 5200 A [2].

\section{FIELD HARMONICS}

\section{A. Notation and Conventions}

It is conventional to report field harmonics in a two dimensional transverse representatiion with the implicit understanding that except for the ends there is no significant longitudinal variation. The representation used here is

$$
B_{x}-B_{y}=Q \underset{n}{\sum_{0}}\left(a_{z}-i b_{n}\right)(z / R)^{n}
$$

where $z=x+i y, R$ is a normalisation radius conventionally taken as $25.4 \mathrm{~mm}$ for Tevatron components, $Q$ is the quadrupole strength in tesla, and $a n\left(b_{4}\right)$ are the skew (normal) harmonic coefficients. In this representation the $a$ and $b$ are dimensionless but their numeric values depend on the choice of $R$. It is conventional to suppress a factor of $10^{-4}$, which results in the harmonic coefficients being reported in "units". The coordinate system origin is such that $a_{0}=b_{0}=0$, i.e., there is no dipole. The coordinate gystem orientation is such that $a_{1}=0$ and $b_{1}=1$. In $a$ perfectly symmetric quadrupole the "allowed" harmonic coefficients $b, n=1,5,9, \ldots$ may have nonsero values determined By details of the design; all other harmonic coefficients would be sero. To the extent that the "non-allowed" harmonics arise from geometric imperfections in the as-built magnets, they are usually independent of excitation current, but aymmetry may also be violated by differences in the properties of the superconductor in the constituent sub-coils. The allowed harmonics show behavior (hysteresis and time dependence) depending on the excitation history.

\section{B. Harmonics Measurement System}

The field harmonics were measured cold using the system previously employed for the Tevatron arc quadrupoles and the initial low bets insertion quadrupoles at BO (CDF) [3]. A loosely fitting flexible double-walled vacuum insulated warm bore was threaded through the magnet beam tube to enable the $2.388 \mathrm{~m}$ long harmonic probe to operate 
at room temperature. The length of the Q2, Q4 (QS) magnets required measuring in 2 (3) end-toend longitudinal position, and combining the data to obtain the average harmonics for the magnet. The trangverse position of the warm bore (and therefore of the harmonic probe) relative to the magnet coil was not mechanically well controlled. It was assumed that the probe rotated with its axis parallel to but displaced from the magnet coil axis; the dipole signal measured by the probe was used to infer the displacement, and the measured harmonics were "shifted" to a coordinate system transversely centered on the magnet. The mechanic of the setup suggested that this method should indicate the probe axis lay below the magnet axis by 1.0 to $2.5 \mathrm{~mm}$.

The run-to-run reproducibility of the low order harmonics of interest was consistently better than 0.1 units. Uncertainties associated with the as-built probe geometry and the validity of the assumptions in the hifting procedure suggest the low order harmonics have an absolute accuracy nearer to \pm 0.5 units.

The dats were taken as follows. A standard excitation "pre-ramp" was done followed by ramping at $25 \mathrm{~A} / \mathrm{s}$ to the first target current. The current was held constant and the measurement started about 60 seconds later. This delay was not well regulated, and to some extent the meaning of the values of the allowed harmonics was degraded by the time dependence effect in these magnets [4]. Upon completion of the measurement at a given current the magnet was ramped at $25 \mathrm{~A} / \mathrm{s}$ to the next target current and the procedure repeated.

\section{Harmonic Data}

Table 2 shows selected harmonic coefficient obtained at a nominal 4250 A excitation on the upramp together with corresponding data from the original Tevatron arc quadrupoles [5].

Table 2

Selected Harmonic Coefficients of 31 Low Beta and -200 Tevatron Are Quadrupoles

$\begin{array}{ccccc}\begin{array}{c}\text { Harmonic } \\ \text { coefficient }\end{array} & \begin{array}{c}\text { Low } \\ \text { (units) }\end{array} & \begin{array}{c}\text { Standard } \\ \text { deviation } \\ \text { (units) }\end{array} & \begin{array}{c}\text { Tevatron arc } \\ \text { Mean } \\ \text { (units) }\end{array} & \begin{array}{c}\text { Standard } \\ \text { deviation } \\ \text { (units) }\end{array} \\ b_{2} & 0.62 & 1.88 & 1.98 & 3.69 \\ a_{2} & -0.43 & \mathbf{3 . 1 1} & 2.83 & 3.41 \\ b_{3} & 0.13 & 0.76 & 1.25 & 0.93 \\ a_{3} & -0.30 & 0.99 & -0.45 & 1.97 \\ b_{4} & 0.15 & 0.48 & -0.26 & 0.74 \\ a_{4} & -0.25 & 0.65 & -0.72 & 0.80 \\ b_{5}^{4} & -\mathbf{3 . 3 8} & 1.62 & -1.91 & 1.70 \\ a_{5} & 0.04 & 0.61 & 0.21 & 0.44 \\ b_{6} & 0.05 & 0.30 & 0.05 & 0.28 \\ a_{6} & 0.11 & 0.37 & 0.18 & 0.29\end{array}$

\section{Discussion of Data}

Coil dimensional data obtained daring fabrication showed the new quadrupoles have more uniform sub-coils than the Tevatron quadrupoles had. So the means of distributions of their nonallowed coefficients were expected to be nearer sero and the distribution widths smaller. Table 2 entries show this has occured. The unexpectedly large width of the a distribution, which has contributions from all four cold masses, is not understood.

The normal 12-pole data are shown in detail in Figure 1. Although the accelerator can tolerate several units of normal 12-pole, an effort was made to keep it small. Unlike the Tevatron arc quadrupoles, where the ends were compactly wound and the body field designed to have sufficient positive $b_{5}$ to compensate for the negative $b_{5}$ in the ends, these new quadrupoles were designed to have nearly zero $b_{5}$ in both the ends and body field separately. A copper wedge was used in the body inner shell, and spacers and different length shells were used in the ends.

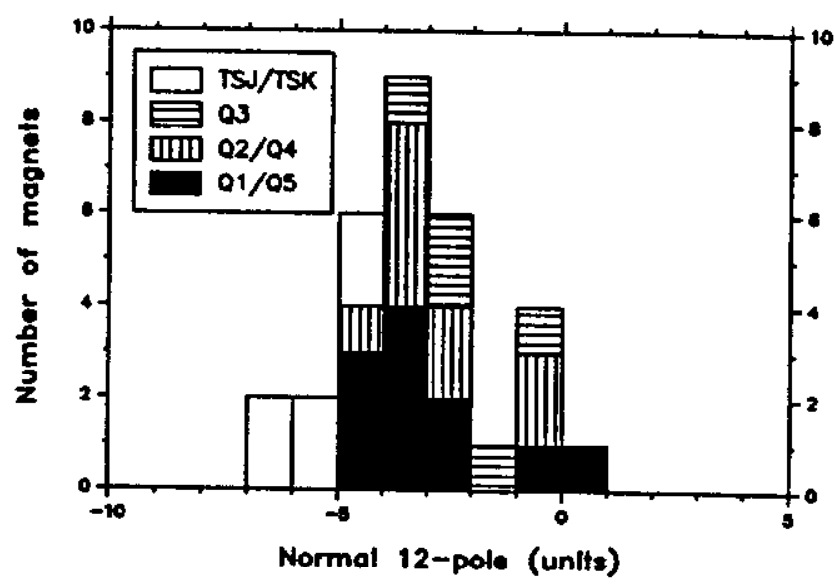

Figure 1. Normal 12-pole data at $4250 \mathrm{~A}$

Data from the Q3's indicate that the average body field $b_{5}=-1.8$ units. The ends have sufficient negative $b_{5}$ to produce in $Q 3$ 's an average total $b_{5}=-2.2$ units. In the short TSJ/TSK spools the negative $b_{5}$ from the ends depresses the average total $b_{b}$ to -5.6 units. The large width of the $b_{5}$ distribution in Table 2 comes in part from combining all four cold mass lengths.

\section{PERIODIC REMNANT FIELD}

Recently at DESY it was observed that in HERA dipoles there is a longitudinal periodicity in the normal sextupole and dipole at $300 \mathrm{~A}$ excitation [6]. The dipole oscillation amplitude is of order $0.05 \mathrm{mT}$ ont of .23 $\mathrm{T}$ and the wavelength corresponds to the twist pitch of the cable and no other longitudinal dimension of the magnet. It is an effect from the superconductor. The effect was subsequently seen in SSC dipoles in the remnant field. There have been conjectures that it is due to 
stend-to-strand variation, possibly arising from coldweids in some strands made during the cabling process.

A hall probe detector was used to study the remnant field of the Q1/Q5 magnet designated as N5401F; it has no known coldwelds. A holder was designed to place two hall probes near the $x$-axis at $x= \pm 15 \mathrm{~mm}$ to sense the total y-component of the field; the sctual probe positions are known only to $\pm 1 \mathrm{~mm}$ due to the mechanics of the warm bore syatem.

Figure 2 shows typical date. The remnant field configuration had been prepared by quenching the magnet, ramping it to a 4800 A flattop for 1200 seconds, and then ramping down to sero current at $200 \mathrm{~A} / \mathrm{s}$. The data were taken at longitudinal intervals of $0.635 \mathrm{~mm}(0.25$ inch); taking one datum required 10 seconds, and an entire scan shown required approximately 900 seconds. The npper trace was initiated $\mathbf{3 2 5 0}$ seconds after the return to sero current. The pronounced longitudinal oscillation has wavelength of $72.0 \pm 0.7 \mathrm{~mm}$, which is close to the cable twist pitch for this magnet. The fall off on the right is due to the probe exiting the end of the magnet. The lower trace was initiated $\$ 40$ seconds after the return to sero current. It is evident that the amplitude of the oscillation decreased with time while the lower trace was being taken left to right, and it decreased further between scans principally by the minima filling. Data taken 2.0, 4.5 and 17.6 hours after return to sero current showed the minims contining to fill but at an ever slower rate.

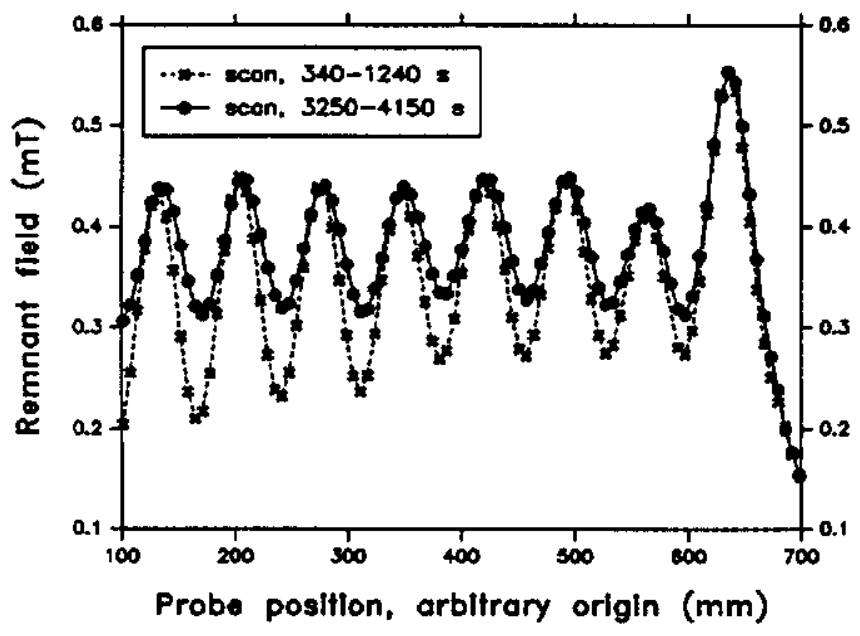

Figure 2. Example of periodic field

Other preparations of the remnant - shorter flattop duration and lower flattop eurrent - reanlt in smaller amplitude oscillations and different time dependences. Note that longitudinal scans made at other places in the two dimensional cross section also show oscillatory behavior with the ame wave length, but with different amplitudes and varying time dependences. And it is not universally true that the amplitude decreases principally by the minima filling.

\section{INTEGRATED FUELD DATA}

The integrated gradient was measured cold using the same stretched wire probe system used for Tevatron are quadrupoles (3). The vagaries of magnet repair enabled N5401F to be measured on four separate occasions. The results suggest a runto-run reproducibility of $\pm 0.05 \%$. Systematic errors are thought to be conviderably larger - of the order $\pm 0.2 \%$.

Table 3

Integrated Field Data at $\mathbf{4 0 0 0 \mathrm { A }}$

Lattice

Designation

Integrated Gradient (Tesla/kA)

TSJ/TSK

Q1/Q5

Q2/Q4

Q3

Lowest Mean Highest

For the shorter two cold mass lengths the difference between weakest and strongest device is about $0.46 \%$. For the 200 original Tevatron $1.68 \mathrm{~m}$ long are quedrupoles production control of the strength was $\pm 0.2 \%[5]$. As expected, in a percentage sense the longer quadrupoles have less atrength variations.

\section{REFERENCES}

[1] A. D. MeIntarff, et al., "The Fermilab Collider DO Low Bete System", European Particle Accelerstor Conference, Rome, Italy, vol. 2, p 1264, June 1988.

[2] S. A. Gouriay, et al., "Quezch Performance of Superconducting Quadrupole Magnets for the New Fermilab Low Beta Insertion", this Conference.

[3] B. C. Brown, et al., "Report on the Production Magnet Measuring System for the Fermilab Energy Sover Superconducting Dipoles and Quadrupoles", IEEE Transactions on Nuclear Science, vol. NS-30, pp. 36083610, August 1983.

[4] M. J. Lamm, et al., "Measurement of Time Dependent Fields in High Gradient Superconducting Quadupoles for the Tevatron", IFEE Transactions on Magnetics, vol. 27-2, Pp. 1811-1814, March 1991.

[5] E. E. Schmidt, et al., "Magnetic Field Data on Fermilab Energy Saver Quadrupolea", IEEE Transections on Nuclear Science, vol. NS-30, pp. 3388-3385, August 1988.

[6] H. Bruck, et al., "Obaervation of a Periodic Pattern in the Peraistent-Current Fields of the Supereonducting HERA Dipole Magnets", DESY Report HERA 91-01, 1991. 
The following paper was presented at the IEEE 1991 Particle Accelerator Conference, San Francisco, California, 6-9 May 1991. Dr. Raymond Hanft is the main author and we want to request 10 copies of this paper to be sent to Dr. Hanft at MS 318. Thank-you.

\section{Magnetic Performance Of New Fermilab}

High Gradient Quadrupoles

R. Hanft, B. C. Brown, J. A. Carson, S. A. Gourlay,

M. J. Lamm, A. D. McInturff, A. Mokhtarani, A. Riddiford

Fermi National Accelerator Laboratory*

P.O. Box 500

Batavia, Illinois 60510 